Check for updates

Cite this as: $B M J 2021 ; 373: n 967$ http://dx.doi.org/10.1136/bmj.n967 Published: 13 April 2021

\section{Drug treatments for covid-19: living systematic review and network meta-analysis}

In this living systematic review and network meta-analysis by Reed Siemieniuk and colleagues (BMJ 2020;370:m2980 doi:) the infographic was updated on 6 April 2021 to version 4.1, to correct an error in version 4, published on 31 March 2021. Values for the mortality outcome (both relative risk and risk difference) were corrected. 